\title{
7,83-Dihydroponasterone A, a New Phytoecdysteroid from the Needles of the Japanese Yew, Taxus cuspidata
}

\author{
Qing-Wen Shi, ${ }^{* a}$ Mei Dong, ${ }^{a}$ Chang-Hong Huo, ${ }^{a}$ Xiao-Hui Su, ${ }^{a}$ Xing Li, $^{a}$ Teiko Yamada ${ }^{b}$ and \\ Hiromasa Kiyota ${ }^{*, b}$
}

\author{
${ }^{a}$ Department of Natural Product Chemistry, School of Pharmaceutical Sciences, Hebei Medical University, 361 \\ Zhongshan East Road, 050017, Shijiazhuang, Hebei Province, P. R. China \\ ${ }^{b}$ Laboratory of Applied Bioorganic Chemistry, Division of Biocience \& Biotechnology for Future Bioindustry, Graduate \\ School of Agricultural Sciences, Tohoku University, 1-1 Tsutsumidori-Amamiya, Aoba-ku, Sendai 981-8555, Japan
}

\begin{abstract}
O novo ecdisteróide 7,8 $\beta$-di-hidroponasterona A e a ponasterona A, foram isolados a partir do extrato metanólico das agulhas do teixo japonês Taxus cuspidata. As estruturas foram elucidadas por meios espectroscópicos, nomeadamente, RMN ${ }^{13} \mathrm{C}$ e ${ }^{1} \mathrm{H}, \mathrm{COSY}{ }^{1} \mathrm{H}-{ }^{1} \mathrm{H}, \mathrm{NOESY}$, HMQC e HMBC, e confirmadas por HR-FABMS.
\end{abstract}

A new plant ecdysteroid 7,8 $\beta$-dihydroponasterone A, together with ponasterone $\mathrm{A}$, were isolated from the methanol extract of the needles of the Japanese yew, Taxus cuspidata. Their structures were elucidated on the basis of spectroscopic analysis including ${ }^{1} \mathrm{H} N M R,{ }^{13} \mathrm{C} N \mathrm{NM}$, ${ }^{1} \mathrm{H}-{ }^{1} \mathrm{H}$ COSY, NOESY, HMQC and HMBC and confirmed by high-resolution FABMS data.

Keywords: Taxus cuspidata, yew, phytoecdysteroid, ponasterone A, 7,8ß-dihydroponasterone A

\section{Introduction}

Phytoecdysteroids are steroidal molecules firstly recognized as hormones controlling mounting and metamorphosis in insects. Today it is realized that these steroids are present at all stages of insect development, regulating many biochemical and physiological processes. ${ }^{1}$ Ecdysteroids and their analogs are also of great interest for medicinal application. ${ }^{2}$ To date, more than 200 phytoecdysteroids were identified, ${ }^{3,4}$ however, only four of them were isolated from the genus Taxus (yew trees). ${ }^{5}$ The Japanese yew, Taxus cuspidata (Taxaceae), is a low trailing bush or tree very popular in Hokkaido and Tohoku regions, widely used as ornamental plant in Japan. Previous phytochemical studies on this species let to the isolation of taxanes with various skeleton, and other classes of compounds. ${ }^{5,6}$ Here we report on the isolation and identification of a new phytoecdysteroids, 7,8 $\beta$-dihydroponasterone A (2), as well as the known ponasterone A (1) from the needles of T. cuspidata.

*e-mail: shiqingwen@hebmu.edu.cn; kiyota@biochem.tohoku.ac.jp

\section{Results and Discussion}

A methanolic extract of the needles of Taxus cuspidata was processed as described in the experimental section to afford compounds $\mathbf{1}$ and $\mathbf{2}$ (Figure 1). Combined analysis of $\mathrm{NMR}^{7}$ and FAB-MS data of compound $\mathbf{1}$, obtained as a white amorphous solid, established its structure as ponasterone $\mathrm{A}$, which has been previously isolated from the bark of T. brevifolia, ${ }^{8}$ T. cuspidata, ${ }^{9}$ and T. yunnanensis. ${ }^{10}$

Compound 2 was obtained as a white amorphous solid with a molecular formula $\mathrm{C}_{27} \mathrm{H}_{46} \mathrm{O}_{6}$ calculated from the peaks at $\mathrm{m} / \mathrm{z} 489.3193(\mathrm{M}+\mathrm{Na})^{+}$and $505.2921(\mathrm{M}+\mathrm{K})^{+}$in the HR-FABMS. The spectroscopic data of 2 (Table 1) closely resembles those of $\mathbf{1}$, with the exceptions that in compound 2 the olefinic carbons and the olefinic proton were absent, the ketone resonance was shifted from $\delta_{\mathrm{C}} 206.4$ to $215.1 \mathrm{ppm}$, and its UV spectrum lacked the characteristic absorption for the $\alpha, \beta$-unsaturated ketone at $242 \mathrm{~nm} .{ }^{11,12}$ Based on these features it was concluded that the structure of $\mathbf{2}$ corresponded to the 7,8-dihydro derivative of $\mathbf{1}$.

The relative stereochemistry of $\mathbf{2}$ was deduced from NOESY data and ${ }^{1} \mathrm{H}-{ }^{-1} \mathrm{H}$ coupling constants of vicinal protons (Figure 2). cis-Fused chair conformation of the 

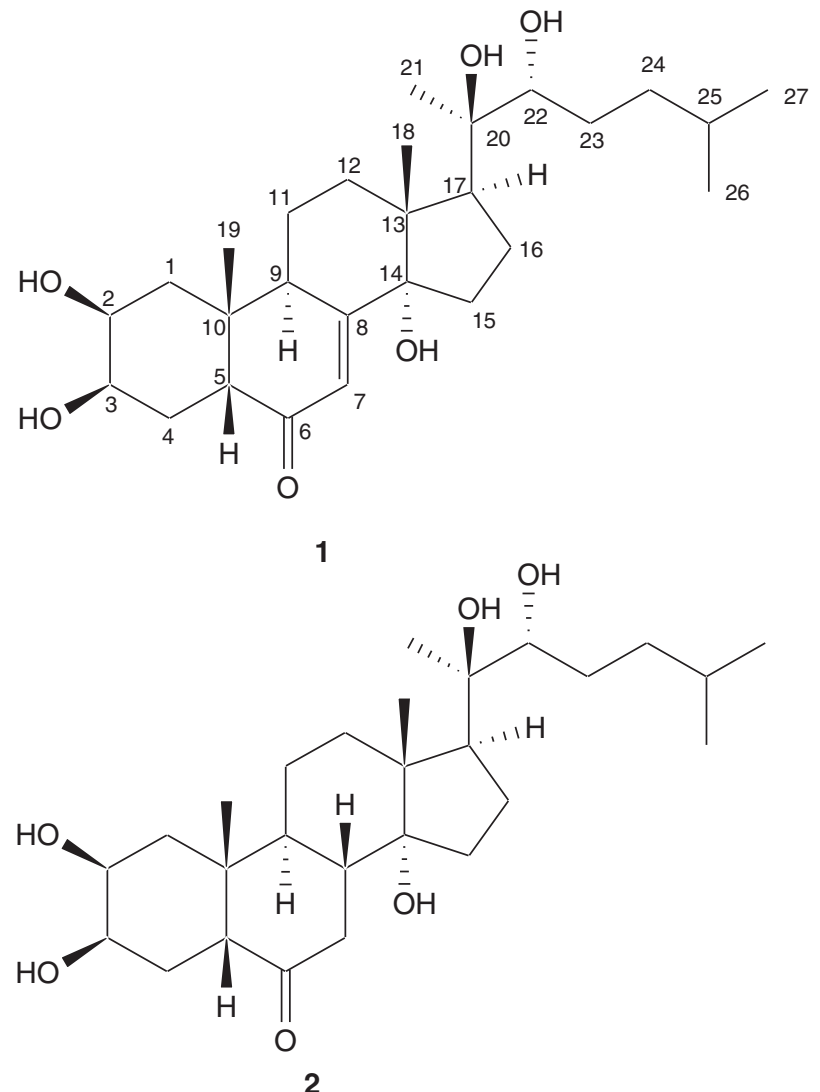

Figure 1. Ponasterone (1) and 7,8 3 -dihydroponasterone (2) isolated from Taxus cuspidata.

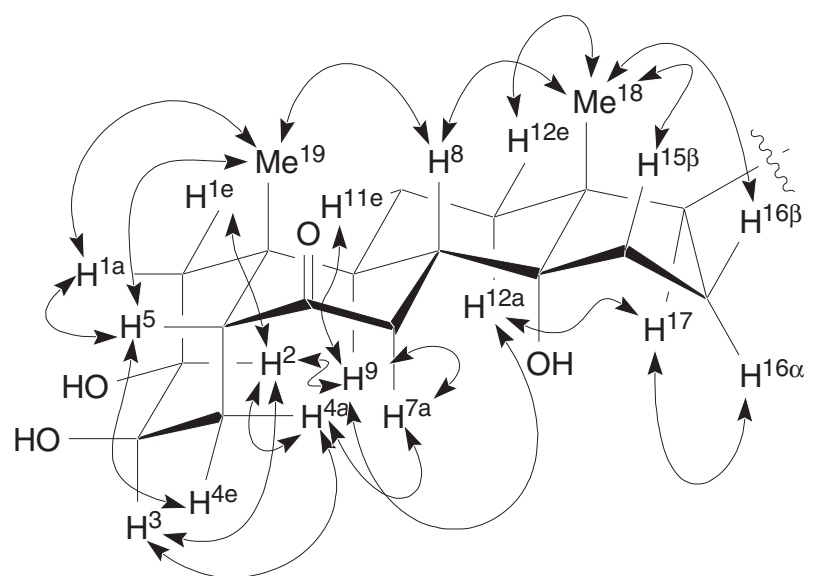

Figure 2. Relative stereochemistry of 7,8 $\beta$-dihydroponasterone A (2). The arrows denote selected NOESY correlations.

$\mathrm{AB}$ rings was elucidated from the coupling constants $\left(J_{1 \mathrm{ax}, 2} 12.3 \mathrm{~Hz}\right.$, and $\left.J_{3,2}=J_{3,4 a x}=J_{3,4 \mathrm{eq}}=2.9 \mathrm{~Hz}\right)$, and the NOESY correlations of H-2 to H-4ax, H-2 to H-9, H-5 to H-19, and H-4ax to H-7ax. The hydroxy groups at $\mathrm{C}-2$ and $\mathrm{C}-3$ were to be $\beta$-oriented, judging from the small coupling constant between $\mathrm{H}-2$ and $\mathrm{H}-3$. The NOE correlations between $\mathrm{H}-7$ ax to $\mathrm{H}-9, \mathrm{H}-8$ to $\mathrm{H}_{3}-18, \mathrm{H}-8$ to $\mathrm{H}_{3}-19$, and $\mathrm{H}-9$ to $\mathrm{H}-12 \mathrm{ax}$ demonstrated the $\mathrm{BC}$ ring was trans-fused. trans-Fusion of the CD-rings was deduced from the similarity of the ${ }^{1} \mathrm{H}$ NMR chemical shifts and coupling constant values to $\mathbf{1}$ and the NOESY correlation of $\mathrm{H}-15 \beta$ to $\mathrm{H}_{3}-18$. The $\beta$-orientation of the side chain $\mathrm{C}-20-\mathrm{C}-27$ was deduced from the NOE between $\mathrm{H}-12 \mathrm{ax}$ to $\mathrm{H}-17$. C-20-OH and $\mathrm{C}-22-\mathrm{OH}$ were assigned to be $\beta$ - and $\alpha$-oriented, respectively, by comparing with the analogous compound. ${ }^{13}$ Consequently, the compound 2 was determined to be $7,8 \beta$ dihydroponasterone. The corresponding $8 \alpha$-diastereomer of 2 was previously synthesized by stereoselective catalytic hydrogenation of $\mathbf{1} .^{14}$

Compound $\mathbf{2}$ was formerly reported as a hypothetical CoMFA model compound to investigate QSAR of ecdysteroids. ${ }^{15}$ Phytoecdysteroids appeared to have agonistic activity at the insectsteroid receptor complex, ${ }^{15,16}$ and participate in the defense of plant against nonadapted phytophagous invertebrates. ${ }^{1,17}$ The fact that yew trees exhibited a very strong resistance to insect pests was considered to be caused by taxanes such as 10deacetylbaccatin III and 10-deacetylbaccatin V. ${ }^{18}$ The presence of $\mathbf{1}$ and $\mathbf{2}$ in the needles of the Japanese yew would also be responsible for insecticidal activity. ${ }^{19}$

\section{Experimental}

\section{General experimental procedure}

Optical rotations: a JASCO DIP-370 digital polarimeter. Flash chromatography: Silica gel 60 (230-400 mesh EM Science). Thin layer chromatography: Silica Gel $60 \mathrm{~F}_{254}$ precoated TLC plates $(0.25 \mathrm{~mm}$ or $0.5 \mathrm{~mm}$, EM Science). Analytical HPLC: a Waters 600 FHU delivery system and a PDA 996 detector, and Whatman partisil 10 ODS-2 (4.6 $\times$ $250 \mathrm{~mm}$ ) column. Preparative HPLC: a Waters Delta Prep 3000 instrument and a UV 486 detector (210 nm, Waters), and Whatman partisil 10 ODS-2 Mag-9 $(9.4 \times 250 \mathrm{~mm})$ or partisil 10 ODS-2 MAG-20 $(22 \times 500 \mathrm{~mm})$ column, eluent: a 50 min linear gradient of acetonitrile ( 25 to $100 \%$ ) in water $\left(18 \mathrm{~mL} \mathrm{~min}^{-1}\right)$. NMR: a Bruker Avance-500 spectrometer (500 MHz for ${ }^{1} \mathrm{H}$ and $125 \mathrm{MHz}$ for ${ }^{13} \mathrm{C}$ ). The solvent was used as an internal reference. FAB-MS: a Vacuum Generators ZAB-HS double-focusing instrument.

\section{Plant material}

The needles of Taxus cuspidata were collected in the autumn of 2000 at Tsutsuzigaoka park, Sendai city in the north-east of Japan. The botanical identification was made by Professor T. Oritani of Toyama Prefectural University, Toyama, Japan. Several voucher specimens have been deposited in the Laboratory of Applied Bioorganic 
Table 1. ${ }^{1} \mathrm{H}$ and ${ }^{13} \mathrm{C}$ NMR data of 2 in $\mathrm{CDCl}_{3}\left(500 \mathrm{MHz}\right.$ for ${ }^{1} \mathrm{H}, 125 \mathrm{MHz}$ for ${ }^{13} \mathrm{C}$ )

\begin{tabular}{|c|c|c|c|c|}
\hline & & 2 & & \\
\hline Position & $\delta\left({ }^{1} \mathrm{H}\right)$ mult. & $J(\mathrm{~Hz})$ & $\delta\left({ }^{13} \mathrm{C}\right)$ & $\mathrm{HMBC}(\mathrm{H} \rightarrow \mathrm{C})$ \\
\hline $1-a x$ & $1.38(\mathrm{~m})$ & & & \\
\hline 1-eq & $1.81(\mathrm{~m})$ & & 37.2 & \\
\hline 2 & $3.82(\mathrm{dt})$ & $12.3,3.8$ & 67.1 & 3 \\
\hline 3 & 4.04 (ddd) & 2.9 & 67.8 & \\
\hline $4-a x$ & $1.99(\mathrm{~m})$ & & 31.9 & \\
\hline 4-eq & $1.84(\mathrm{~m})$ & & & \\
\hline 5 & $2.42(\mathrm{dd})$ & $13.5,3.9$ & 53.3 & $4,6,9,10,19$ \\
\hline 6 & & & 215.1 & \\
\hline \multirow[t]{2}{*}{7 -ax } & $2.55(\mathrm{dd})$ & & & \\
\hline & $2.06(\mathrm{dd})$ & $14.3,12.014 .3,3.6$ & 37.0 & 8,14 \\
\hline 8 & $2.14(\mathrm{~m})$ & & 39.1 & \\
\hline 9 & $2.18(\mathrm{~m})$ & & 32.8 & $8,10,11,12,19$ \\
\hline 10 & & & 40.0 & \\
\hline $11-a x$ & $1.46(\mathrm{~m})$ & & & \\
\hline $11-e q$ & $1.79(\mathrm{~m})$ & & 20.2 & \\
\hline $12-a x$ & $1.84(\mathrm{~m})$ & & & \\
\hline 12-eq & $1.60(\mathrm{~m})$ & & 32.2 & \\
\hline 13 & & & 47.8 & \\
\hline 14 & & & 84.7 & \\
\hline $15 \beta$ & $1.84(\mathrm{~m})$ & & & \\
\hline $15 \alpha$ & $1.35(\mathrm{~m})$ & & 32.3 & \\
\hline $16 \beta$ & $1.99(\mathrm{~m})$ & & & \\
\hline $16 \alpha$ & $1.65(\mathrm{~m})$ & & 20.4 & \\
\hline 17 & $2.21(\mathrm{t})$ & 9.3 & 49.3 & $13,15,16,18,20,21$ \\
\hline 18 & $1.00(\mathrm{~s})$ & & 17.4 & $12,13,14,17$ \\
\hline 19 & $0.91(\mathrm{~s})$ & & 22.9 & $1,5,9,10$ \\
\hline 20 & & & 76.9 & \\
\hline 21 & $1.18(\mathrm{~s})$ & & 20.3 & 17,22 \\
\hline 22 & 3.38 (br.d) & 8.6 & 76.6 & 21,24 \\
\hline $23 \mathrm{a}$ & $1.46(\mathrm{~m})$ & & & \\
\hline $23 b$ & $1.22(\mathrm{~m})$ & & 29.3 & \\
\hline $24 \mathrm{a}$ & $1.44(\mathrm{~m})$ & & & \\
\hline $24 b$ & $1.21(\mathrm{~m})$ & & 36.3 & \\
\hline 25 & $1.54(\mathrm{~m})$ & & 27.9 & \\
\hline 26 & 0.91 (d) & 6.4 & 22.9 & 24,27 \\
\hline 27 & 0.90 (d) & 6.4 & 22.5 & 24,26 \\
\hline
\end{tabular}

Chemistry, Graduate School of Agricultural Sciences, Tohoku University, Japan.

\section{Extraction and isolation}

Air-dried needles of Taxus cuspidata were ground (3.0 $\mathrm{kg}$ ) and extracted with $8 \mathrm{~L}$ of methanol for one week at room temperature. The plant material was filtered, and extracted again with fresh solvent for another two times (each time with $4 \mathrm{~L}$ solvent, total $16 \mathrm{~L}$ ) in seven days. The combined organic extracts were evaporated under reduced pressure. Water (2 L) was added, and lipids were removed by stirring the mixture with hexane $(3 \times 2 \mathrm{~L})$. The aqueous phase was then salted $(\mathrm{NaCl}, 150 \mathrm{~g})$ and extracted with $\mathrm{CH}_{2} \mathrm{Cl}_{2}(4 \times 1 \mathrm{~L})$. The combined $\mathrm{CH}_{2} \mathrm{Cl}_{2}$ extracts were dried with anhydrous sodium sulfate, filtered and evaporated yielding a dark green extract $(45 \mathrm{~g})$. A portion of the methylene chloride extract ( $38 \mathrm{~g}$ ) was absorbed onto silica gel (45 g) and packed on a wet column chromatography (silica gel, $820 \mathrm{~g}$ ). Successive elution with $\mathrm{CH}_{2} \mathrm{Cl}_{2}-\mathrm{MeOH}$ gradient with increasing amounts of methanol from 5\% to 45\% (total $10 \mathrm{~L}$ ) yielded 32 fractions $\left(\mathrm{Fr}_{\mathrm{D}-1}\right.$ to $\left.\mathrm{Fr}_{\mathrm{D}-32}\right)$. $\mathrm{Fr}_{\mathrm{D}-27}$ to $\mathrm{Fr}_{\mathrm{D}-30}$ were combined (14 g) and chromatographed over silica gel $(470 \mathrm{~g})$, being eluted with a stepwise hexane-acetone gradient $(1: 1,3: 4,2: 3)$ to yield 28 fractions $\left(\mathrm{Fr}_{\mathrm{D}-27-1}\right.$ to $\left.\mathrm{Fr}_{\mathrm{D}-27-28}\right)$. The fractions $\mathrm{Fr}_{\mathrm{D}-27-16}, \mathrm{Fr}_{\mathrm{D}-27-17}$ and $\mathrm{Fr}_{\mathrm{D}-27-18}(640 \mathrm{mg})$ were pooled and re-chromatographed over silica gel $(50 \mathrm{~g})$ eluting with hexane-EtOAc $(1: 2)$ to yield 17 fractions $\left(\mathrm{Fr}_{\mathrm{D}-27-16-1}\right.$ to $\left.\mathrm{Fr}_{\mathrm{D}-27-16-17}\right)$. The fractions $\mathrm{Fr}_{\mathrm{D}-27-16-14}(18 \mathrm{mg})$ and $\mathrm{Fr}_{\mathrm{D}-27-16-15}(21 \mathrm{mg})$ were combined and applied to preparative HPLC to yield $1(7 \mathrm{mg}$, $\left.\mathrm{t}_{R}=22.32 \mathrm{~min}\right) . \mathrm{Fr}_{\mathrm{D}-27-19}$ to $\mathrm{Fr}_{\mathrm{D}-27-28}(1.59 \mathrm{~g})$ were absorbed onto $3.0 \mathrm{~g}$ silica gel and re-chromatographed over silica gel, being eluted using stepwise gradients of $\mathrm{CH}_{3} \mathrm{CN}$ in 
$\mathrm{CH}_{2} \mathrm{Cl}_{2}$ to give 25 fractions $\left(\mathrm{Fr}_{\mathrm{D}-27-19-1}\right.$ to $\left.\mathrm{Fr}_{\mathrm{D}-27-19-25}\right) . \mathrm{Fr}_{\mathrm{D}-27-19-24}$ (170 mg) was subjected to preparative HPLC. The material eluted at $\mathrm{t}_{R}=20.18$ min was collected and concentrated $(25 \mathrm{mg})$, and further purified by preparative TLC with EtOAc-EtOH (100:6) elution, to yield 2 (3.5 mg, $\left.R_{f}=0.40\right)$.

\section{Ponasterone A (1)}

Amorphous solid; $[\alpha]_{\mathrm{D}}^{22}+68^{\circ}$ (c $\left.0.20, \mathrm{MeOH}\right)$.

\section{7,8 $\beta$-Dihydroponasterone $A$ (2)}

Amorphous solid; $[\alpha]_{\mathrm{D}}^{22}+76^{\circ}(c 0.20, \mathrm{MeOH}) ;{ }^{1} \mathrm{H}$ and ${ }^{13} \mathrm{C}$ NMR spectral data, see Table 1. HRFABMS: $\mathrm{m} / \mathrm{z}$ $489.3193[\mathrm{M}+\mathrm{Na}]^{+}$(Calc. for $\mathrm{C}_{27} \mathrm{H}_{46} \mathrm{O}_{6} \mathrm{Na}, 489.3192$ ), 505.2921 $[\mathrm{M}+\mathrm{K}]^{+}$(Calc. for $\mathrm{C}_{27} \mathrm{H}_{46} \mathrm{O}_{6} \mathrm{~K}, 505.2931$ ).

\section{Acknowledgments}

We thank Scientific Research Foundation for the Returned Overseas Chinese Scholars, State Education Ministry of China and the Foundation for Researching New Drugs of China for the financial support in part. No: 2003AA2Z3527.

\section{Supplementary Information}

Supplementary data of compound $\mathbf{1}$ are available free of charge at http://jbcs.sbq.org.br, as PDF file.

\section{References}

1. Dinan, L.; Phytochemistry 2001, 57, 324.

2. Akhren, A. A.; Kovganko, N.V.; Ekdisteroidy: Khimia I Biologicheskaya Aktivnost (Ecdysteroids: Chemistry and Biological Activity), Nauka I Tekhnika: Minsk, 1989.

3. Nakanishi, K.; Koreeda, M.; Sasaki, L.; Chang, M. L.; Hsu, H. Y.; J. Chem. Soc., Chem. Commun. 1966, 915.

4. Lafont, R.; Wilson, I. D.; The Ecdysone Handbook, $2^{\text {nd }}$ ed., The Chromatographic Society: Nottingham, UK, 1996; http:// ecdybase.org/, accessed in February 2006.
5. Parmar, V. S.; Jha, A.; Bish, K. S.; Taneja, P.; Sight, S. K.; Kumar, A.; Poonam, J. R; Olsen, C. E.; Phytochemistry 1999, 50, 1267.

6. Baloglu, E.; Kingston, D. G. I.; J. Nat. Prod. 1999, 62, 1448; Kobayashi, J.; Shigemori, H.; Med. Res. Rev. 2002, 22, 305 and references cited therein; Shi, Q. W.; Kiyota, H.; Chem. Biodivers. 2005, 2, 1597; Shi, Q. W.; Oritani, T.; Horiguchi, T.; Sugiyama, T.; Murakami, R.; Yamada, T.; Biosci., Biotechnol., Biochem. 1999, 63, 924; Shi, Q. W.; Oritani, T.; Sugiyama, T.; Horikuchi, T.; Murakami, R.; Zhao, D.; Oritani, T.; Tetrahedron 1999, 55, 8365.

7. Vokác, K.; Budesinsky, M.; Harmatha, J.; Kohoutová, J.; Phytochemistry 1998, 49, 2109.

8. Rao, K. V.; Bhakuni, R. S.; Hanuman, J. B.; Davies, R.; Johnson, J.; Phytochemistry 1996, 41, 863.

9. Imai, S.; Nakanishi, K.; Koreeda, M; Kurokawa, T.; Steroids 1967, 10, 557; Ripa, P. V.; Martin, E. A.; Cocciolone, S. M.; Adler, J. H.; Phytochemistry 1990, 29, 425; Takemoto, T.; Hikino, Y.; Jin, H., Hikino, H.; Yakugaku Zasshi 1968, 88, 359.

10. Li, S. H.; Zhang, H. J.; Yao, P.; Niu, X. M.; Xiang, W.; Sun, H. D.; J. Asian Nat. Prod. Res. 2002, 4, 147.

11. The UV absorption was checked by the UV detecter for HPLC.

12. Costantino, V.; Carmela D.; Fattorusso, E.; Mangoni, A.; Steroids 2000, 65, 138.

13. Ruan, B.; Wilson, W. K.; Schroepfer Jr., G. J.; Steroids 1999 , 64, 385 .

14. Suksamrarn, A.; Tanachatchairatana, T., Sirigarn, C.; Tetrahedron 2002, 58, 6033.

15. Dinan, L.; Hornann, R. E.; Fujimoto, T.; J. Comput. Aid. Mol. Des. 1999, 13, 185.

16. Dinan, L.; Savchenko, T.; Whiting, P.; Sarker, S.D.; Pestic. Sci. 1999, 55, 331.

17. Slama, K.; Lafont, R.; Eur. J. Entomol. 1995, 92, 355.

18. Daniewski, W. M.; Gumulka, M.; Anczewski, W.; Masnyk, M.; Bloszyk, E.; Gupta, K. K.; Phytochemistry 1998, 49, 1279.

19. Horn, D. H. S. In Naturally Occurring Insecticides; Jacobson, M.; Crosby, D. G., eds.; Marcel Dekker: New York, 1971, p. 333.

Received: November 1, 2006 Web Release Date: August 10, 2007 


\section{7,8ß-Dihydroponasterone A, a New Phytoecdysteroid from the Needles of the Japanese Yew, Taxus cuspidata}

\section{Qing-Wen Shi, ${ }^{*, a}$ Mei Dong, ${ }^{a}$ Chang-Hong Huo, ${ }^{a}$ Xiao-Hui Su, ${ }^{a}$ Xing Li $^{a}{ }^{a}$ Teiko Yamada ${ }^{b}$ and Hiromasa Kiyota ${ }^{*, b}$}

${ }^{a}$ Department of Natural Product Chemistry, School of Pharmaceutical Sciences, Hebei Medical University, 361 Zhongshan East Road, 050017, Shijiazhuang, Hebei Province, P. R. China

${ }^{b}$ Laboratory of Applied Bioorganic Chemistry, Division of Biocience \& Biotechnology for Future Bioindustry, Graduate School of Agricultural Sciences, Tohoku University, 1-1 Tsutsumidori-Amamiya, Aoba-ku, Sendai 981-8555, Japan

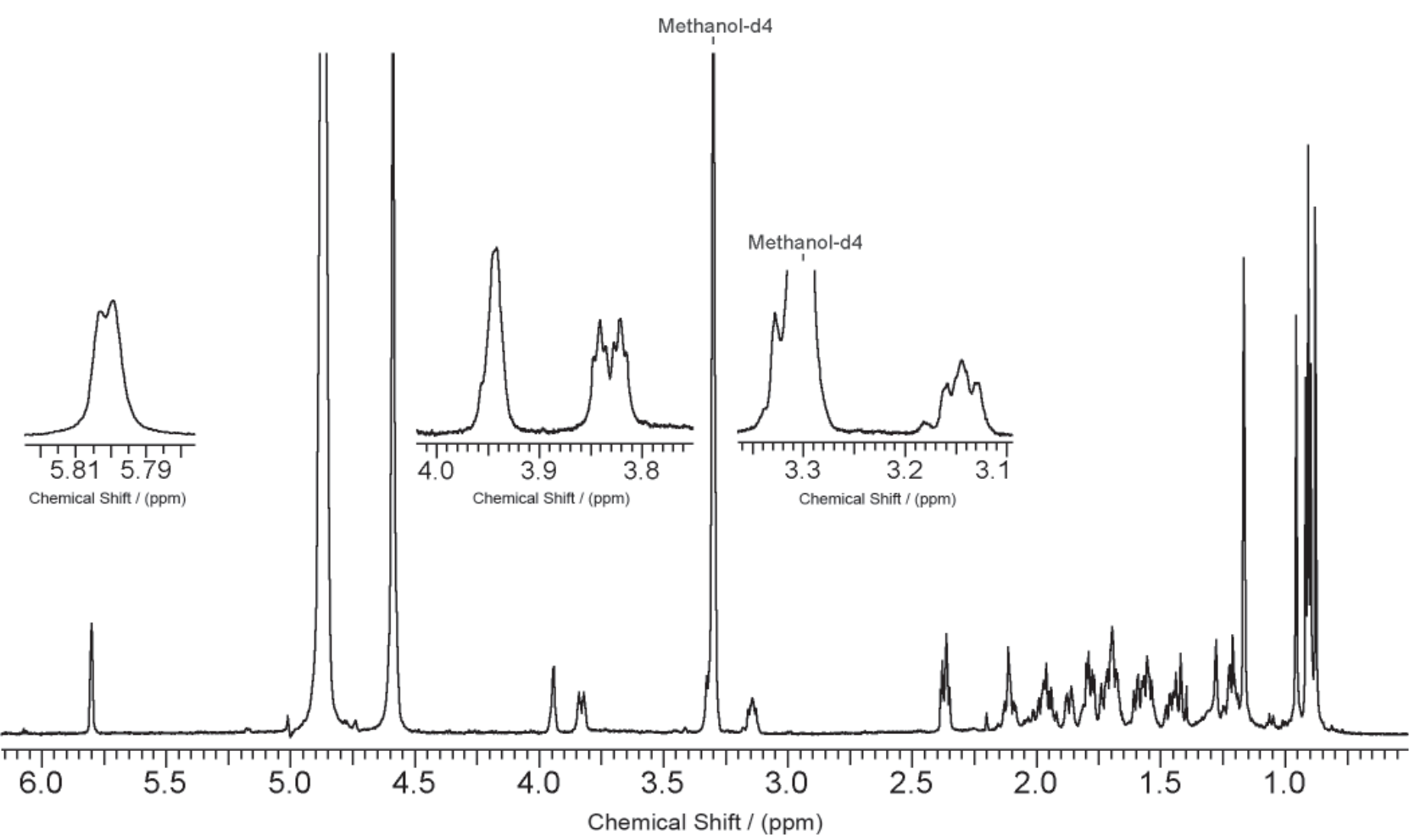

Figure S1. ${ }^{1} \mathrm{H}$ NMR data of compound $\mathbf{1}$ in $\mathrm{CDCl}_{3}(500 \mathrm{MHz})$.

*e-mail: shiqingwen@hebmu.edu.cn; kiyota@biochem.tohoku.ac.jp 


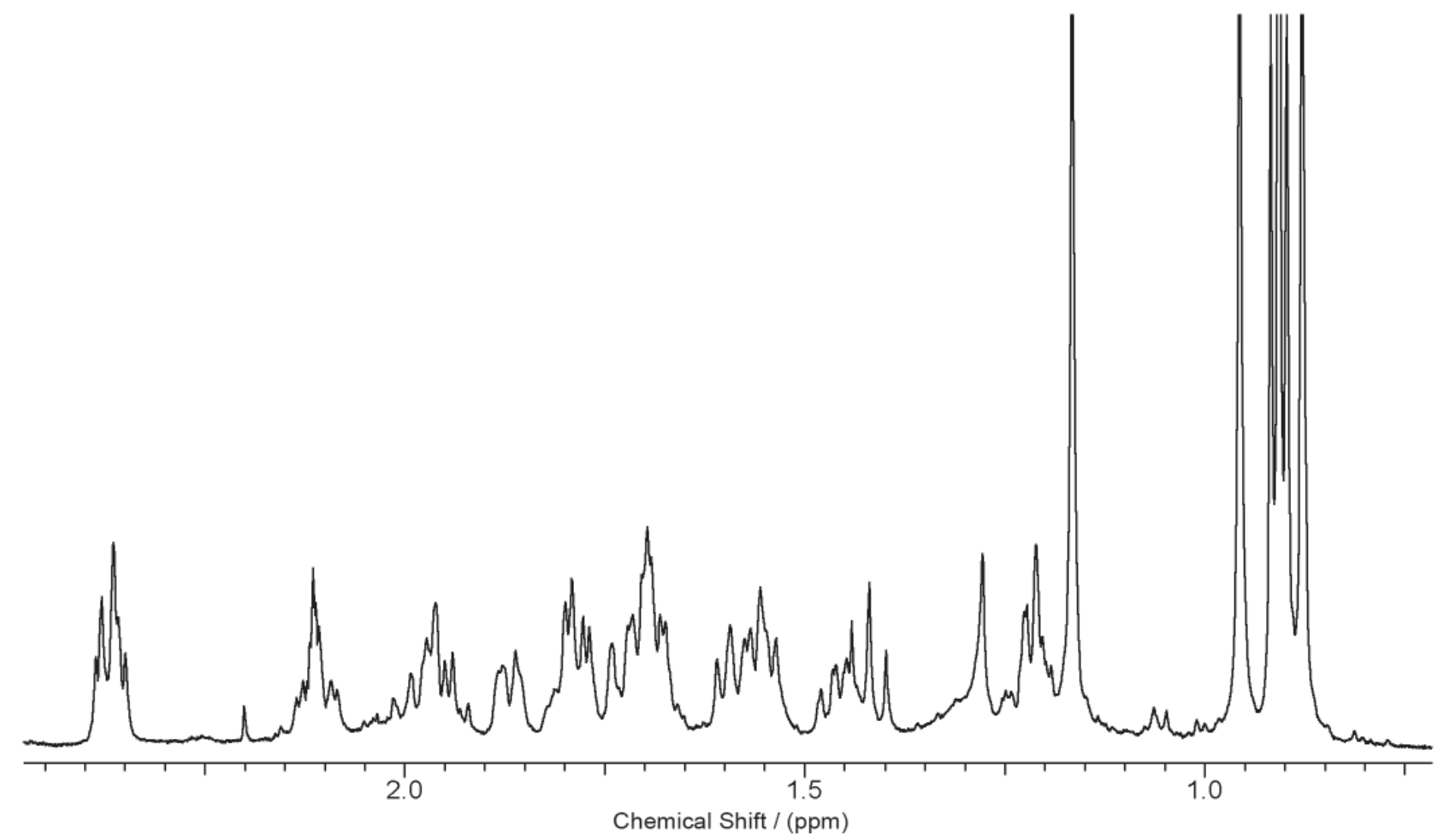

Figure S2. ${ }^{1} \mathrm{H}$ NMR data of compound $\mathbf{1}$ in $\mathrm{CDCl}_{3}(500 \mathrm{MHz})$. 